\title{
Study on the Industrial Structure of Guangxi Based on Production Function
}

\author{
Xiao Jijun ${ }^{1, a}$, Guo Manhua ${ }^{2, b}$ and Shen $\mathrm{Ye}^{3, \mathrm{c}}$ \\ 1,2 , ${ }^{3}$ Business School of Guilin University of Electronic Technology Guilin, Guangxi , 541004, China \\ axyd312@qq.com, ${ }^{b} 772630264 @ q q . c o m,{ }^{c} 1540023625 @ q q . c o m$
}

Keywords: Manufacturing; Service Industry; Industrialization.

Abstract. The inner evolution process of industrialization were studied by the mechanism of the industrialization and Cobb-Douglas production function. The data from 2004 to 2014 in the national, Guangdong province and Guangxi province were quoted to study the trend of the industrial structure variation.The results showed that marginal effect and growth of manufacturing industry were greater than that of the services in the middle of industrialization. Agriculture capital and labors were transferred to manufacturing industry. There is a negative correlation relationship of the manufacturing with, service industry and agriculture. The growth rate of service industry is faster than the manufacturing industry near the end of the mid-industrialization. This is the integration period of service and manufacturing, It appears a service-oriented manufacturing advanced production model.

\section{Introduction}

The word of industrialization in the related work of Marx and Engels is not seen. Industrialization in the initial stage is just a spontaneous social phenomenon. In the Britain's industrial revolution, mechanical production of the large-scale production replaced the original production model. The original production mode has been unable to meet capacity of the growing market demand .Professor Gong Weiping ${ }^{[1]}$ of Jinan University believes that industrialization is a historical stage of universal significance in the development of human society. It is also a historical process of social production, which is based on the mechanical industry. He believed that the study of the nature of industrialization should be carried out from three levels: economic development, social change and the evolution of civilization. Feng Bing ${ }^{[2]}$ thinks that industrialization is a typical transformation process from traditional agricultural society to modern industrial society, the transformation process has the following obvious characteristics: agricultural labor force flowing to manufacturing, city absorbing rural surplus labor and urban population exceeding the number of rural population. This is to say that the industrialization is a process of the breakthrough change from junior to senior and transformation of production factors. Economists Chenery, Syrquin ${ }^{[3]}$ and other economists in the industrialization process of the industrial structure evolution law, by studying the output as a share of GDP, and with the aid of the multinational model, changed the economic growth as the comprehensive economic structure, and then put forward the standard model. This model was based on the level of per capita gross domestic product (GDP) to determine a period of industrialization. However, this model lacks of considering the value of time. The scholars of various countries had carried on different perspectives on industrialization, from the conceptual model to the mathematical model. but these studies have not directly response to the inherent mechanism of industrialization. This article is based on all above. The evolution of industrialization mechanism. was explained from the Douglas production function

\section{Status of industrialization in Guangxi}

Guangxi's industrial development is still a relatively low level, and there is a great gap compared with the national and global. Although the industrialization of Guangxi has benefited from the development of China-ASEAN and the Beibu Gulf Economic Zone in recent years. It has made some progress, for its starting late. The task of industrialization is still very arduous. Wen Shuangyan ${ }^{[4]}$ at the stage of industrialization in Guangxi deduced that in the mid-industrialization in Guangxi, compared to the 
developed areas of China .There is a long distance. Yang Yafei ${ }^{[5]}$ also believes that the basic level of industrialization in the Guangxi Zhuang Autonomous Region has been in the early stages of the mid-industrialization, There are at the early stage of industrialization to the middle of the transition in some places. Lv Yongquan ${ }^{[6]}$ pointed out that Guangxi's manufacturing industry overall backward. Its main features are below : The level of the manufacturing industry is generally low, poor competitiveness; Capability of independent technological innovation is generally weak. Technological progress is slow; The low level of cooperation in the region and the development of production service industry lags behind; The total amount of value added of the manufacturing industry is small; The proportion of GDP is low.

\section{Build the model assumptions and commentary}

Model Premise Condition.(1)The paper was based on agriculture, manufacturing, services on behalf of the first, second and third industry respectively. The extractive industries also is not considered as a natural resources to improve social productivity of factors of production;(2) Factors of production in the industry are transferred between follow clark theorem;(3) The three major industries are objective existence and the phenomenon there is no completely replace in the process of industrialization. At the beginning of the industrialization, the first industry cannot completely replace the third industry. The third industry can't replace the first industry in late industrialization. Namely ,services cannot completely replace the agriculture.

Cobb-douglas Production Function and Its Analysis. In order to further explore the relationship of industrialization and the urbanization with agriculture, manufacturing, and services. The agriculture, manufacturing and service industries are to be as the research object. The product prices of agriculture ,manufacturing. and services are quoted for the production of variable. Different stages of industrialization were as the premise condition of a mathematical model. The service product is low, so we don't consider services output in the early stage of the industrialization. Social gross domestic product is equal to the gross agricultural and manufacturing. Corresponding Cobb-douglas production function form is established. Function of agricultural production such as Eq.1, manufacturing production function as shown Eq.2.

$$
Y_{1}=A_{1} K_{1}^{\partial_{1}} L_{1}^{\beta_{1}} \mu_{1}
$$

$$
Y_{2}=A_{2} K_{2}^{\partial_{2}} L_{2}^{\beta_{2}} \mu_{2}
$$

When, marginal productivity and manufacturing labor marginal productivity of agricultural labor force equivalent relations are as formula $P_{L_{1}}=\frac{\partial_{Y_{1}}}{\partial_{L_{2}}}, P_{L_{2}}=\frac{\partial_{Y_{2}}}{\partial_{L_{2}}}$ The agricultural capital marginal productivity and manufacturing marginal productivity equal relations are as formula $P_{K_{1}}=\frac{\partial_{Y_{1}}}{\partial_{K_{1}}}, P_{K_{2}}=\frac{\partial_{Y_{2}}}{\partial_{K_{2}}}$ When the economy is in the early stage of the industrialization. Agricultural accumulation of capital and Labor efficiency is higher than them of manufacturing industry.

when the economy is to be as part of the industrialization in the middle. Manufacturing replaces agricultural status in the whole national economy. The emergence of services with manufacturing begin to grow. When, manufacturing is to balance with agriculture. The surplus agricultural labor force and capital are transferred to manufacturing. According to the assumptions above, service industry to absorb capital and labor is equivalent to manufacturing lost the capital and labor, regardless of the output factors of agricultural production. Manufacturing product such as Eq.3 and services such as GDP Eq.4 constitute the social product Eq.5. When manufacturing labor marginal productivity is equal to the services marginal labor productivity and, the state is balance. Yes, capital is so recursive. Manufacturing gross domestic product is higher than previous industrialized manufacturing gross domestic product .Its necessary condition is Eq.6.

$$
\begin{aligned}
& Y_{3}=f\left(Y_{4}\right)\left(K_{2}-K_{4}\right)^{\partial_{2}}\left(L_{2}-L_{4}\right)^{\partial_{2}} \mu_{2} \\
& Y_{4}=A_{4} K_{4}^{\partial_{4}} L_{4}^{\beta_{4}} \mu_{4}
\end{aligned}
$$




$$
\begin{aligned}
& P_{L_{3}}=\frac{\partial_{Y_{3}}}{\partial_{\left(L_{2}-L_{4}\right)}}, P_{L_{4}}=\frac{\partial_{Y_{4}}}{\partial_{L_{4}}} \\
& f\left(Y_{4}\right)\left(K_{2}-K_{4}\right)^{\partial_{2}}\left(L_{2}-L_{4}\right)^{\partial_{2}} \mu_{2}>A_{2} K_{2}^{\partial_{2}} L_{2}^{\beta_{2}} \mu_{2}
\end{aligned}
$$

This period the scale of agriculture is diminishing its returns. On the contrary, the manufacturing scale is increasing itself returns. At the same time, the manufacturing labor wage is higher than that for agricultural labor force. So the agricultural sector labor force will be transferred to the manufacturing department . There are also part of the agricultural sector labor force to flow into services department. But the size of the service sector is in a state of diminishing returns. Manufacturing and services are the same city. Transformation of population promotes the development of industrialization and urbanization. At this point we should be supporting the manufacturing industry as the leading industry. The benefits of manufacturing production scale is in a state of decline in the late industrialization. Completely on the contrary, returns of services production scale are increasing. Service of productivity increasing breaks the original equilibrium. Service industry accepts labors and capital from agriculture and manufacturing respectively. Manufacturing productivity must be greater than that before in the late industrialization. The progress of technology makes up for the loss of manufacturing labor and capital. Technology progress makes up for the loss of manufacturing labor and capital. Services at the same time broaden the manufacturing sales market.

\section{Metrological Verification}

Based on previous studies, this paper verified the structure changes in the middle of the industrialized and the end of the industrial through the research of the respective industrial structure of Guangdong ,Guangxi and the National .We take the ratio of first, second and third largest industry output separately accounted for GDP from 2004 to 2014.The data 's source, comes from national bureau of statistics. As shown in Fig.1.
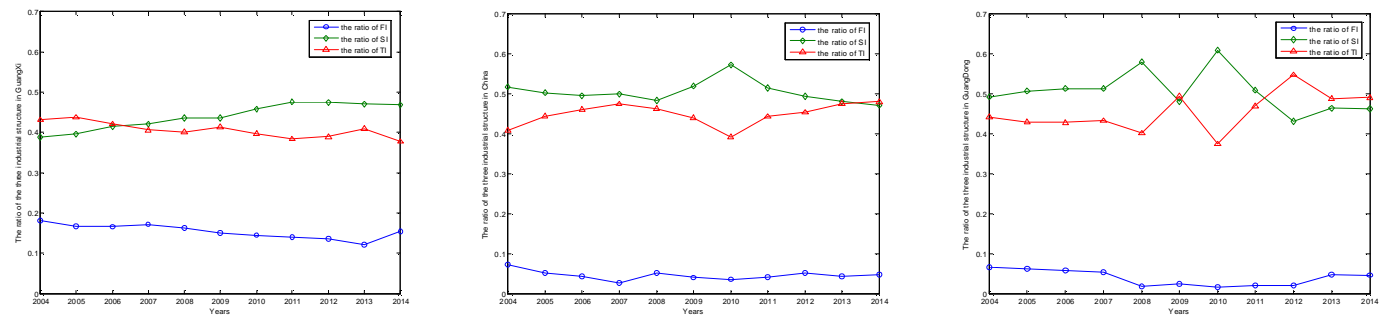

Fig.1 The industrial structure changes of Guangxi, the National, Guangdong province from 2004 to 2014.

From the perspective of the trend of Fig.1, Guangxi, Guangdong province and the national industry structure belonged to the middle of industrialization in the 11 years from 2004 to 2014. Guangdong province, Guangxi province and the country was in different state in the intermediate industrialization. In these three areas, Guangdong was best and followed by the nation. The last was the Guangxi province. The three industrial structure of Guangxi in 2004 was $0.181,0.388,0.431$. Although the proportion of service industry is higher than manufacturing, the proportion of agriculture was too big .GDP per capita is low, The proportion of service industry is relatively low, no more than $50 \%$, not like the industrial structure of developed countries. Guangxi services increased from $43.1 \%$ to $37.8 \%$;manufacturing rose from $38.8 \%$ to $46.8 \%$; agriculture has fallen from $18.1 \%$ to $15.4 \%$.In the manufacturing sector growth is faster than the services and agriculture while verifying the proposition 1.Manufacturing marginal effect value was greater than marginal effect value services and agriculture. The industrialization of Guangdong province was faster in Guangxi province, closing to the end of industrialized. The proportion of service industry of Guangdong province rose to $44.2 \%$ from $49.1 \%$, manufacturing from $49.2 \%$ to $46.2 \%$ during this period. Agriculture had fallen from $6.6 \%$ to $4.7 \%$.So marginal effect marginal effect is greater than the manufacturing service industry and agriculture. Capital and labor in manufacturing industry began to shift to service industry. 


\section{Conclusions}

At the beginning of the industrialization, the economy is characteristic with the agricultural economy, most social labor and capital in agriculture. In the middle of the industrialization, manufacturing marginal effect value and growth are greater than the service industry and agriculture. Capital and Labor are transported to the manufacturing industry. There is a negative correlation relationship of the manufacturing with service industries and agriculture. Close to mid-end of industrialization, services grew faster than manufacturing industry. This is the period, of the service and manufacturing integration. It appears a service-oriented manufacturing advanced production model. The service industry occupies the dominant position of the economy as a whole in the late industrialization.

\section{Acknowledgements}

This work was financially supported by Humanities and Social Science Key Project of Guangxi Education Department (ZD2014055), Innovation Project of Guangxi Graduate Education (YCSW2015156).

\section{References}

[1] Gong Wei ping. Industrial category theory - the system study of marxist theory of industrialization [M]. Beijing: economic management publishing house, 2001.

[2] Feng Bing Zheng Lingli. Industrialization theory and a new road to industrialization in China [J]. Journal of trade, the ten-day era, 2007.P45-45.

[3] Hollis B. Chenery etc. In the comparative study of industrialization and economic growth [M]. Shanghai: Sanlian Bookstore, 1989.

[4] Wen Shuang Yuan, Liu Nan and Wang Ying. Guangxi industrialization in phase and existing problems of research [J]. Journal of management, 2013 (8).

[5] Ya-fei Yang. Guide the analysis of underdeveloped regions in industrialization, evaluation of the transformation of the pattern of economic development and the level of industrialization of guangxi and the path [J]. Journal of economic and social development, 2013, (5).

[6] Lv Yongquan. Guangxi manufacturing industry sustainable and healthy development countermeasures study [J]. Journal of economic and social development, 2010, (10).

[7] Toffel, M. W. Contracting for Servicizing[D]. Haas School of Business University of California-Berkeley Working Paper, May, 2002.

[8] Reiskin, E. D., White, A.l., Kauffman Johnson,J. and Votta, T. J. Servicizing the Chemical Supply Chain[J]. Journal of Industrial Ecoloygy, 2000, P19-31. 